\title{
INTEGRASI EMPAT PILAR PENDIDIKAN (UNESCO) MELALUI PENDIDIKAN HOLISTIK BERBASIS KARAKTER DI SMP MUHAMMADIYAH 1 PRAMBANAN
}

\author{
Wikanti Iffah Juliani ${ }^{1}$, Hendro Widodo ${ }^{2}$ \\ Magister Pendidikan Agama Islam Universitas Ahmad Dahlan \\ Email : wikanti.iffah@gmail.com
}

\begin{abstract}
Education is an attempt to find information that is useful for life. Learning to know something (learning to know) becomes an effort that is done in getting useful knowledge and that is not useful. Knowledge and experience gained are then applied to solve problems that arise and get a change. This mastery of knowledge will lead students to find their true identity and develop their potential. After all these learning processes are passed, a student will be able to adapt to the environment and carry out his role in the community. Learning outcomes that students will get depend on the contribution of the curriculum that has been made. Therefore, in making a curriculum, it is pursued according to needs, not fragmented and can reflect all aspects thoroughly and contextually. The integrity requires a good character to make it clearer in bringing out a complete person.
\end{abstract}

Keywords: Four pillars of education, curriculum, holistic education

\begin{abstract}
Abstrak
Pendidikan merupakan sebuah usaha untuk mencari informasi yang berguna bagi kehidupan. Belajar untuk mengetahui sesuatu (learning to know) menjadi sebuah usaha yang dilakukan dalam mendapatkan pengetahuan untuk membedakan hal-hal yang bermanfaat dan yang tidak bermanfaat. Pengetahuan dan pengalaman yang diperoleh selanjutnya diaplikasikan untuk memecahkan masalah yang muncul dan mendapatkan sebuah perubahan. Penguasaan terhadap ilmu pengetahuan inilah yang akan mengantarkan siswa menemukan jati dirinya dan mengembangkan potensi yang dimiliki. Setelah semua proses belajar tersebut dilalui maka seorang siswa akan mampu beradaptasi di lingkungan dan menjalankan perannya di dalam masyarakat. Hasil belajar yang akan diperoleh siswa juga bergantung pada kontribusi kurikulum yang telah dibuat. Oleh karena itu dalam pembuatan sebuah kurikulum diupayakan sesuai dengan kebutuhan, tidak terkotak-kotak dan dapat merefleksikan seluruh aspek secara menyeluruh dan kontekstual. Keutuhan tersebut membutuhkan karakter yang baik agar semakin memperjelas dalam memunculkan pribadi yang paripurna.
\end{abstract}

Kata kunci: Empat pilar pendidikan, kurikulum, pendidikan holistik 


\section{PENDAHULUAN}

Peningkatan kualitas pendidikan dipengaruhi oleh faktor-faktor yang terlibat di dalam proses pendidikan dan pembelajaran, seperti guru, kurikulum, sarana prasarana dan lingkungan. Perlu adanya usaha dengan membuat sebuah pondasi yang kuat agar kualitas pendidikan ini dapat tercapai. Masalah yang muncul dan sering kita dengar dari berbagai media menandakan bahwa pondasi dari pendidikan mulai terabaikan (Laksana, 2016). Berkenaan dengan banyaknya masalah yang muncul tersebut maka UNESCO (United Nations Educational Scientific and Cultral Organization) menggagas Empat Pilar Pendidikan untuk meningkatkan kualitas pendidikan suatu bangsa. Empat Pilar tersebut meliputi learn to know, learn to do, learn to be, dan learn to live together. Diharapkan dengan adanya pondasi dari empat pilar ini maka menjadi jawaban dari permasalahan yang muncul mengenai pendidikan dan melahirkan siswa yang mampu berkarya dan dapat menjalankan perannya di lingkungan masing-masing.

Perkembangan ilmu pengetahuan dan teknologi yang semakin pesat menyebabkan perubahan prinsip belajar manusia. Adanya perkembangan itulah yang membuat UNESCO membuat 4 pilar pendidikan sebagai upaya mempersiapkan pembelajaran di era abad 21 (Tilaar, 1998).

Berdasarkan penjelasan di atas, Empat Pilar Pendidikan yang dicanangkan UNESCO dapat kita artikan sebagai konsep pendidikan yang mengoptimalkan kemampuan siswa dalam menjalankan perannya di lingkungan atau masyarakat. Hal ini sejalan dengan konsep pendidikan holistik yang bertujuan memunculkan individu yang memiliki pribadi utuh dan menyeluruh (intelektual, emosional, fisik, sosial, estetik, dan spiritual). Oleh karena itu, penelitian ini akan menggambarkan integrasi Empat Pilar Pendidikan dari UNESCO yang diimplementasikan dengan pendidikan holistik di SMP Muhammadiyah 1 Prambanan.

\section{Learning To Know}

Learning to know merupakan prinsip bahwa belajar adalah untuk mengetahui atau memahami. Prinsip pembelajaran ini harus dikondisikan agar siswa aktif dan menciptakan suasana untuk selalu ingin mengetahui dan memahami sesuatu yang baru. Dengan demikian pembelajaran hendaknya menciptakan sikap 'penasaran' pada murid, sehingga murid selalu ingin belajar lebih jauh (Sukiyasa, 2013). 
Pilar pertama ini merupakan pintu gerbang pertama masuknya ilmu pengetahuan, maka keaktifan siswa sangatlah penting. Hal ini juga merupakan suatu hal mendasar dalam keberhasilan proses pembelajaran. Metode yang menarik dan inovatif dapat digunakan oleh pendidik untuk memberikan stimulus agar siswa aktif untuk mencari informasi-informasi baru. Keaktifan tersebut dapat berupa fisik dan keaktifan psikis (Nugroho, 2016).

Langkah-langkah yang dapat dilakukan oleh guru untuk membangkitkan keaktifan siswa menurut Moh. Uzer Usman (1993) diantaranya adalah:

1. Memberikan motivasi sebelum pembelajaran dimulai

2. Menjelaskan tujuan instruksional

3. Mengingatkan kompetensi belajar

4. Memberikan stimulus berupa masalah, topik, dan konsep yang akan dipelajari

5. Memunculkan aktifitas, partisipasi peserta didik dalam kegiatan pembelajaran

6. Memberikan umpan balik (feedback);

7. Melakukan tagihan-tagihan kepada peserta didik berupa tes sehingga kemampuan peserta didik selalu terpantau dan terukur;

8. Menyimpulkan setiap materi yang disampaikan diakhir pembelajaran.

9. Menyimpulkan setiap materi yang disampaikan diakhir pembelajaran.

10. Keaktifan dapat ditingkatkan dan diperbaiki dalam keterlibatan siswa pada saat belajar

\section{Learning To Do}

Pilar yang kedua adalah learning to do yang menekankan pentingnya berinteraksi dengan lingkungan dan memecahkan masalah yang muncul. Kemampuan soft skill dan hard skill sangat dibutuhkan dalam penguatan pilar ini. Karena sesungguhnya pendidikan merupakan bagian penting dalam penyiapan SDM (Sumber Daya Manusia) yang berkualitas, dan cakap dalam menghadapi perkembangan jaman dengan cara mengembangkan seluruh potensi yang dimilikinya (Laksana, 2016). Hard skill merupakan penguasaan ilmu pengetahuan, teknologi, dan kemampuan teknis yang berhubungan dengan bidang ilmunya (Safrudin, 2018), sedangkan soft skill merupakan keterampilan di luar keterampilan teknis (Makmun, 2017). Dua kemampuan yang 
dimiliki oleh setiap individu, jika dikembangkan secara seimbang maka akan menumbuhkan jiwa atau pribadi yang berkualitas.

\section{Learning To Be}

Pilar ketiga ini adalah usaha yang dilakukan pendidik agar siswa dapat mencari jati dirinya sesuai dengan kemampuan yang dimiliki baik itu hard skill maupun soft skill. Terkait proses pencarian jati diri, terdapat beberapa sumber yang mempengaruhi pembentukan identitas diri pada remaja yaitu :

1. Lingkungan sosial, dimana remaja tumbuh dan berkembang seperti keluarga, tetangga dan kelompok teman sebaya.

2. Kelompok acuan (reference group), yaitu kelompok yang terbentuk pada remaja misalnya kelompok agama atau kelompok yang memiliki minat yang sama dimana melalui kelompok tersebut remaja dapat memperoleh nilai-nilai dan peran yang dapat menjadi acuan bagi dirinya.

3. Tokoh idola, yaitu seseorang yang sangat berarti seperti sahabat, guru, kakak, atau orang yang mereka kagumi.

\section{Learning To Live Together}

Pilar yang terakhir inilah yang akan mengantarkan siswa untuk memahami dan manyadari bahwa dirinya merupakan bagian dari lingkungannya. Ketika siswa telah menyadari bahwa dirinya adalah bagian dari masyarakat maka akan menumbuhkan rasa toleransi dan tanggung jawab dalam menjalankan perannya.

\section{Pendidikan Holistik}

Pendidikan holistik menurut Miller yang dikutip Widyastono (2018) merupakan pendidikan yang mengembangkan dengan harmonis seluruh kemampuan individu yang meliputi intelektual, emosi, fisik, sosial, estetika, fisik, dan spiritual. Keterhubungan antar bagian dengan keseluruhan merupakan fokus dalam pendidikan holistik. Hubungan yang dimaksud adalah hubungan antara berpikir linier dan intuitif, hubungan antara pikiran dan jasad, hubungan antara ranah berbagai ilmu pengetahuan, hubungan antara individu dan masyarakat, dan hubungan antara diri dan diri.

Tujuan yang ingin dicapai dengan adanya pendidikan holistik ini adalah mengembangkan potensi setiap individu dalam suasana belajar yang menyenangkan, 
demokratis, dan humanis. Diharapkan pada akhirnya siswa akan menemukan jati dirinya (learning to be) sehingga memperoleh kebebasan psikologis dalam menentukan keputusan dengan cara yang sesuai dengan dirinya.

\section{Kurikulum}

Menurut pandangan yang lampau kurikulum memiliki pengertian kumpulan mata pelajaran yang disampaikan oleh guru kepada peserta didik. Anggapan tersebut masih mengakar dalam benak masyarakat umum yang menjadikan gambaran kurikulum. Kurikulum yang menjadi jantungnya, pendidikan tentunya harus dikenal dengan benar oleh masyarakat tentang konsepnya yang sebenarnya (Arifin, 2018).

Kurikulum menurut UU Sisdiknas No. 20 Tahun 2003 adalah seperangkat rencana pengaturan mengenai tujuan, isi dan bahan pelajaran serta cara yang digunakan sebagai pedoman dalam penyusunan kurikulum tingkat satuan Pendidikan dan silabusnya pada setiap satuan Pendidikan. Sedangkan secara etimologi, kurikulum berasal dari bahasa Yunani (Syamsul, 2012) yaitu curir yang artinya pelari dan curare yang berarti tempat berpacu (Idi, 2007). Dalam Bahasa latin curriculum berarti $a$ running, course, or race course kemudian dalam Bahasa Prancis courir yang memiliki arti berlari . Dari beberapa pengertian bahasa latin tersebut kemudian digunakan istilah 'courses' atau mata pelajaran yang harus ditempuh untuk mendapatkan suatu gelar.

Secara terminologi, pengertian kurikulum telah banyak dikemukakan oleh para ahli (2014) diantaranya:

1. Menurut Crow kurikulum merupakan sebuah rancangan pengajaran atau sejumlah mata pelajaran yang telah disusun secara sistematik guna menyelesaikan suatu program dalam upaya meraih gelar atau memeroleh ijazah.

2. Menurut Arifin kurikulum merupakan seluruh bahan pelajaran yang harus disajikan dalam proses kependidikan dalam suatu sistem institusional Pendidikan.

3. Menurut Mac Donald (1965) dalam Nana Syaodih S (2017) kurikulum merupakan suatu rencana yang memberi pedoman atau pegangan yang digunakan dalam berlangsungnya proses kegiatan belajar-mengajar.

Mengingat fungsi kurikulum dalam proses pendidikan adalah alat untuk mencapai tujuan pendidikan, maka sebagai alat pendidikan kurikulum memiliki bagian- 
bagian penting dan bagian penunjang yang dapat mendukung operasinya dengan baik. Bagian-bagian ini disebut komponen yang saling berkaitan, berinteraksi dalam upaya mencapai tujuan komponen-komponen yang merangkainya dan saling berkaitan satu dengan yang lain seperti yang disampaikan oleh Nana Syaodih dalam (Subhi, 2016) diantaranya adalah tujuan, isi atau materi, proses atau sistem penyampaian serta medianya, dan evaluasi.

Komponen kurikulum diantaranya adalah : tujuan, isi, dan strategi. Selaku lembaga pendidikan, sekolah mempunyai sejumlah tujuan yang ingin dicapainya yang digambarkan dalam bentuk pengetahuan, keterampilan dan sikap yang diharapkan dapat dimiliki siswa setelah mereka menyelesaikan seluruh program pendidikan dari sekolah tersebut. Tujuan yang ingin dicapai dibedakan menjadi dua yaitu tujuan yang ingin dicapai sekolah secara keseluruhan, dan tujuan yang ingin dicapai pada setiap mata pelajaran. Kurikulum berisi tentang materi pelajaran yang disiapkan untuk mencapai tujuan pendidikan. Adapun strategi erat kaitannya dengan pendekatan, metode, serta teknik mengajar.

\section{METODE}

Metode yang digunakan dalam penelitian ini adalah kualitatif dan dilaksanakan di SMP Muhammadiyah 1 Prambanan. Pengumpulan data menggunakan teknik wawancara, observasi dan dokumentasi. Kemudian data yang diperoleh dianalisis menggunakan model analisis interaktif Matthew B. Miller.

\section{HASIL DAN PEMBAHASAN}

\section{Profil SMP Muhammadiyah 1 Prambanan}

SMP Muhammadiyah 1 Prambanan merupakan sebuah lembaga pendidikan tingkat menengah pertama milik Muhammadiyah di bawah Pimpinan Daerah Muhammadiyah Sleman yang terletak di perbatasan provinsi DIY dan Jawa Tengah. Kondisi ini berdampak pada karakteristik peserta didik yang beragam dari segi kultural, intelektual, serta bakat dan minat. Peserta didik dengan berbagai macam bakat dan kemampuan inilah yang akhirnya mendorong sekolah untuk memberikan fasilitas ekstrakurikuler yang meliputi berbagai aspek intelektual dan keterampilan yang 
dimiliki. Hal ini sejalan dengan konsep pendidikan holistik untuk memaksimalkan semua potensi peserta didik sehingga menjadi pribadi yang utuh.

\section{Integrasi Empat Pilar Pendidikan dalam Kurikulum SMP Muhammadiyah 1}

\section{Prambanan}

Berdasarkan hasil wawancara, observasi, dan dokumentasi yang dilakukan di SMP Muhammadiyah 1 Prambanan, diperoleh data yang sesuai dengan fokus penelitian. Bentuk integrasi Empat Pilar Pendidikan dari UNESCO di sekolah ini tercantum dalam dokumen KTSP sekolah yang menjadi acuan penyelenggaraan kegiatan pembelajaran untuk mencapai tujuan pendidikan. Empat pilar yang meliputi learning to know, learning to do, learning to be, and learning to live together diintegrasikan ke dalam model pendidikan berbasis holistik sekolah baik dalam pembelajaran di kelas ataupun kegiatan pembiasaan di sekolah.

Bentuk integrasi empat pilar dan karakteristik pendidikan holistik terlihat jelas dalam visi sekolah yaitu "Islami, Unggul dalam Prestasi, Berdaya Saing dan Mandiri". Bentuk integrasi lainnya dapat dijabarkan sebagai berikut :

1. Pembiasaan Sholat Dhuha, Dhuhur dan 10 menit tadarus Al-Qur'an

Lingkungan yang Islami akan menciptakan suasana sekolah yang penuh religiusitas yang nantinya mampu mencetak peserta didik yang berimbang antara intelektual dan spiritual. Keseimbangan antara intelektual dan spiritual inilah yang nantinya kan menjadi bekal peserta didik menjadi pribadi yang utuh untuk menapaki masa depan. Pembiasaan shalat Dhuha dan Dhuhur berjamaah dan tadarus bersama 10 menit sebelum pembelajaran dimulai akan menumbuhkan sikap kedisiplinan dan penguatan ketaqwaan peserta didik bahkan seluruh warga sekolah.

2. Prestasi akademik dan non akademik.

Potensi peserta didik yang beragam hendaknya juga menjadikan sekolah lebih peka dalam menyediakan segala macam fasilitas. Potensi yang diasah sesuai dengan bakat dan minat akan mampu mengarahkan peserta didik dalam menemukan jati dirinya (learning to be). Hal ini ditunjukkan dengan presstasi di tahun pelajaran sebelumnya, salah satunya mampu menjuarai perlombaan 
olimpiade Matematika tingkat SMP Muhammadiyah se DIY dan lomba egrang bathok dalam Olimpiade Budaya Jawa se DIY.

3. Integrasi kepedulian lingkuangan dalam Rencana Pelaksanaan Pembelajaran (RPP)

Penanaman kepedulian dengan lingkungan sekitar juga terlihat dengan adanya pencantuman wawasan mitigasi bencana dalam RPP di sekolah, mengingat sekolah ini juga terkena dampak gempa bumi tahun 2006 di DIY sehingga bangunan sekolah rata dengan tanah. Letak daerah Prambanan yang berada pada sesar Opak yang terbentang dari Bantul hingga Prambanan yang menyebabkan wilayah ini rawan terdampak gempa bumi. Adanya kepedulian sosial ini akan menjadikan peserta didik paham akan perannya dalam masyarakat.

4. Penguatan Pendidikan Karakter

Pada era digital seperti saat ini banyak sekali arus informasi yang dengan bebasnya dapat diakses oleh peserta didik. Berbagai macam informasi tanpa filter dapat mengakibatkan degradasi moral generasi muda. Budaya hedonistis mulai tampak dengan semakin konsumtif dengan segala kemudahan yang ditawarkan oleh perkembangan jaman. Berbelanja, menonton film, mengakses game juga sangat mudah sekali dilakukan dengan hanya sekali sentuh pada layar handphone. Oleh karena itu, berdasarkan hal tersebut sekolah menyikapi dengan menguatkan kembali pendidikan karakter dengan mengintegrasikannya, khususnya dalam kurikulum baik dalam pembelajaran maupun pembiasaan di sekolah.

Bentuk-bentuk integrasi pendidikan karakter di SMP Muhammadiyah Prambanan berupa :

a. Etika Lalu lintas

Penguatan etika berlalu lintas dicantumkan dalam silabus dan RPP semua mata pelajaran dan disampaikan ketika pembelajaran di kelas. Hal ini dikarenakan banyaknya remaja yang mengendarai kendaraan bermotor padahal belum memiliki surat ijin mengemudi. Jumlah korban kecelakaan juga semakin meningkat dari kalangan remaja yang belum mempunyai SIM. Harapannya setelah adanya penguatan etika lalu lintas akan memberikan kesadaran bagi peserta didik untuk lebih tertib di jalan raya. 


\section{b. Program Zero Waste}

Permasalahan yang sering dihadapi adalah permasalahan sampah yang menyebabkan dampak negatif bagi lingkungan. Salah satu bentuk kepedulian kita akan permasalahan sampah adalah dengan memanfaatkan kembali agar lebih berdaya guna. Kegiatan yang dilakukan adalah pemilahan sampah dengan menyediakan tempat sampah yang sesuai dengan kebutuhan di sekolah yaitu terdiri dari sampah plastik, organik, dan kertas. Selain itu sampah dari botol bekas dijadikan satu dan dimanfaatkan menjadi ecobrick yang selanjutnya dijadikan kerajinan sofa. Hal ini juga sebenarnya termasuk proses learning to live together yaitu peserta didik sadar akan perannya sebagai agen penjaga lingkungan agar tetap bersih dan sehat.

\section{KESIMPULAN}

Potensi yang bermacam-macam yang dimiliki oleh peserta didik merupakan hal yang perlu dikembangkan dalam rangka menemukan jati diri. Strategi yang dilakukan salah satunya adalah dengan mengintegrasikan empat pilar pendidikan dari UNESCO dan penerapan pendidikan holistik di sekolah seperti yang dilakukan oleh SMP Muhammadiyah 1 Prambanan. Adanya penerapan ini akan memunculkan generasi yang utuh dalam mengembangkan potensi dirinya. Keseimbangan antara pengetahuan umum, spiritual, dan pendidikan karakter yang tertuang dalam kurikulum maupun berbagai program sekolah merupakan sarana yang ditempuh untuk mencapai tujuan tersebut. Pembiasaan kegiatan-kegiatan untuk menanamkan pendidikan karakter disisi lain juga menumbuhkan sisi religius dari peserta didik. Poin penting dalam menyukseskan program sekolah yang telah dilaksanakan adalah berkat kerjasama dan dukungan antara warga sekolah dan lingkungan di sekitar sekolah.

\section{DAFTAR PUSTAKA}

Abdullah, Idi. Pengembangan Kurikulum Teori Dan Praktik. Yogyakarta: Ar-Ruzz Media, 2007.

Laksana, Sigit Dwi. "Integrasi Empat Pilar Pendidikan (UNESCO) Dan Tiga Pilar Pendidikan Islam.” Al-Idarah 6, no. 1 (2016): 43-61.

Makmun, Hana. Life Skill Personal Self Awareness. Yogyakarta: Deepublish Publisher, 
2017.

Nugroho, Wibowo. "Upaya Peningkatan Keaktifan Siswa Melalui Pembelajaran Berdasarkan Gaya Belajar Di Smk Negeri 1 Saptosari.” ELINVO 1, no. 2 (2016): 128-39. https://doi.org/10.21831/elinvo.v1i2.10621.

Numadiah. "Kurikulum Pendidikan Agama Islam.” Al-Afkar III, no. II (2014).

Safrudin, Sri Mulyati, Rosni Lubis. Pengembangan Kepribadian Dan Keprofesionalan Bidan. Malang: Wineka Media, 2018.

Subhi, Tb. Asep. “Konsep Dasar, Komponen dan Filosofi Kurikulum PAI.” Qathruna 3, no. 1 (2016): 117-34.

Sukiyasa, Kadek. "Pengaruh Media Animasi Terhadap Hasil Belajar Dan Motivasi Belajar Siswa Materi Sistem Kelistrikan Otomotif." Jurnal Pendidikan Vokasi Jurnal 3, no. 1 (2013): 129.

Syamsul, Huda Rohmadi. Pengembangan Kurikulum Agama Islam. Yogyakarta: Araska, 2012.

Tilaar H.A.R. Beberapa Agenda Reformasi Pendidikan Nasional. Magelang: Tera Indonesia, 1998.

Usman, Uzer. Upaya Optimalisasi Kegiatan Belajar Mengajar. Bandung: PT. Remaja Rosdakarya, 1993.

Widyastono, Herry. "Muatan Pendidikan Holistik Dalam Kurikulum Pendidikan Dasar Dan Menengah.” Jurnal Pendidikan Dan Kebudayaan 18, no. 4 (2018): 467. https://doi.org/10.24832/jpnk.v18i4.102.

Zainal, Arifin. Manajemen Pengembangan Kurikulum Pendidikan Islam: Teori Dan Praktik. Yogyakarta: UIN Press, 2018. 